\title{
Measurement and analysis of horizontal vibration response of pile foundations
}

\author{
A. Boominathan ${ }^{\mathrm{a}, *}$ and R. Ayothiraman ${ }^{\mathrm{b}}$ \\ ${ }^{a}$ Department of Civil Engineering, Indian Institute of Technology Madras, Chennai, India \\ ${ }^{\mathrm{b}}$ Department of Civil Engineering, Indian Institute of Technology Guwahati, Guwahati, India
}

Received 20 December 2004

Accepted 10 March 2006

\begin{abstract}
Pile foundations are frequently used in very loose and weak deposits, in particular soft marine clays deposits to support various industrial structures, power plants, petrochemical complexes, compressor stations and residential multi-storeyed buildings. Under these circumstances, piles are predominantly subjected to horizontal dynamic loads and the pile response to horizontal vibration is very critical due to its low stiffness. Though many analytical methods have been developed to estimate the horizontal vibration response, but they are not well validated with the experimental studies. This paper presents the results of horizontal vibration tests carried out on model aluminium single piles embedded in a simulated Elastic Half Space filled with clay. The influence of various soil and pile parameters such as pile length, modulus of clay, magnitude of dynamic load and frequency of excitation on the horizontal vibration response of single piles was examined. Measurement of various response quantities, such as the load transferred to the pile, pile head displacement and the strain variation along the pile length were done using a Data Acquisition System. It is found that the pile length, modulus of clay and dynamic load, significantly influences the natural frequency and peak amplitude of the soil-pile system. The maximum bending moment occurs at the fundamental frequency of the soil-pile system. The maximum bending moment of long piles is about 2 to 4 times higher than that of short piles and it increases drastically with the increase in the shear modulus of clay for both short and long piles. The active or effective pile length is found to be increasing under dynamic load and empirical equations are proposed to estimate the active pile length under dynamic loads.
\end{abstract}

Keywords: Active pile length, clay, dynamic bending moment, horizontal vibration, natural frequency, pile stiffness

\section{Introduction}

The increasing use of pile foundations in power plants, petrochemical complexes and earthquake prone areas, offshore platforms and our limited knowledge and understanding of nonlinear soil-pile-structure interaction under dynamic loads, have contributed to the recent interest and activity in the dynamic analysis of soil-pile-structure systems. It has been observed and experienced that these piles are subjected to predominantly horizontal dynamic loads resulting from operating machineries, wind, ocean waves and earthquakes. Case histories on the analyses of pile foundation failures during recent earthquakes [31] revealed that the omission of pile design to dynamic/seismic loads is the major cause for failures and insisted upon the necessity of study on the analysis and design of soil-pile system to horizontal dynamic loads. Various methods, namely, Equivalent Cantilever Approach [13], Novak's Continuum Approach [19], Subgrade Reaction method [29] and Lumped Mass Idealization method [33] were proposed for the evaluation of horizontal dynamic response of piles based on the assumption of linear behaviour of soil. However, the field observation carried out by various investigators $[2,7,11,16,20,24,30,33,38,41]$ show large discrepancy between the observed and estimated values of horizontal dynamic response due to nonlinear behaviour of soil and gapping

\footnotetext{
*Corresponding author. E-mail: boomi@iitm.ac.in.
} 
Table 1

Properties of Clay

\begin{tabular}{lc}
\hline Properties & Value \\
\hline Gravel, \% & 1.0 \\
Sand, \% & 25.0 \\
Silt, \% & 32.5 \\
Clay, \% & 41.5 \\
Specific Gravity & 2.54 \\
Liquid limit, \% & 74.0 \\
Plastic limit, \% & 26.0 \\
Plasticity index, \% & 48.0 \\
Classification (as per D2487-00) & Fat Clay $(\mathrm{CH})$ \\
Shear strength, Su, kN/m ${ }^{2}$ & \\
$\mathrm{I}_{c} \approx 0.0$ & 3.5 \\
$\mathrm{I}_{c}=0.15$ & 9.3 \\
$\mathrm{I}_{c}=0.30$ & 13.7 \\
$\mathrm{I}_{c}=0.60$ & 31.6 \\
\hline
\end{tabular}

effect at the pile-soil interface in clays. Study on the dynamic soil-pile interaction problem using the finite element method was initially attempted $[8,28]$, but approximately considering the nonlinear behaviour of soil and damping characteristics. Review of dynamic analysis of piles using the finite element method [3,39] revealed that the rigorous dynamic finite element analysis involves a 3-D analysis with proper boundary conditions accounting for radiation damping, which requires a large computational effort and cost. In recent years, few models have been proposed accounting the nonlinear behaviour of soil $[4,9,10,18,22,23,25,34,36,37,40]$ to study the soil-pile interaction under inertial and seismic lateral loads and an overview of various linear and nonlinear methods of dynamic analysis was presented in [3]. Although these models have been proposed to study the dynamic soil-pile interaction accounting the nonlinear behaviour, a lot need to be still learned through parametric studies and experimental investigations.

Literature on the experimental studies on model piles embedded in clays under horizontal dynamic loads and parametric studies are very limited [12,21,27,35]. It is well known that the active pile length is an important parameter in the design of piles subjected to horizontal loads [15], but the effect of horizontal dynamic loads on the active pile length is not clearly understood yet. Therefore, in the present work, comprehensive experimental investigations are envisaged and the work has been accomplished accordingly by carrying out extensive and fully instrumented laboratory experiments on the horizontal vibration response of single piles embedded in clay. This paper presents the results of experimental investigation carried out on model single piles embedded in clay at a simulated Elastic Half Space. The influence of various parameters namely, pile length (L), magnitude of dynamic load ( $\left.\mathrm{F}_{o}\right)$ and shear modulus of clay $\left(\mathrm{G}_{s}\right)$ on the horizontal dynamic response of piles embedded in clay are rigorously investigated. Based on the measurement, analysis and interpretation of experimental data, empirical equations are proposed to determine the depth of maximum dynamic bending moment $\left(z_{m d}\right)$ and thereby the active pile length under dynamic lateral loads.

\section{Materials}

\subsection{Soil}

Index and engineering properties of clay determined from laboratory tests are presented in Table 1 . The soil is classified as $\mathrm{CH}$ - Fat clay as per ASTM classification [1].

\subsection{Instrumented pile}

Aluminum model piles with an outer diameter of $25 \mathrm{~mm}$ and thickness of $3 \mathrm{~mm}$ were used. The length to diameter ratio $(\mathrm{L} / \mathrm{d})$ of piles was varied from 10 to 40 to cover the behaviour of both short rigid piles and long flexible piles based on the relative stiffness of the soil-pile system. A solid conical driving shoe was fixed at the pile tip to enhance 


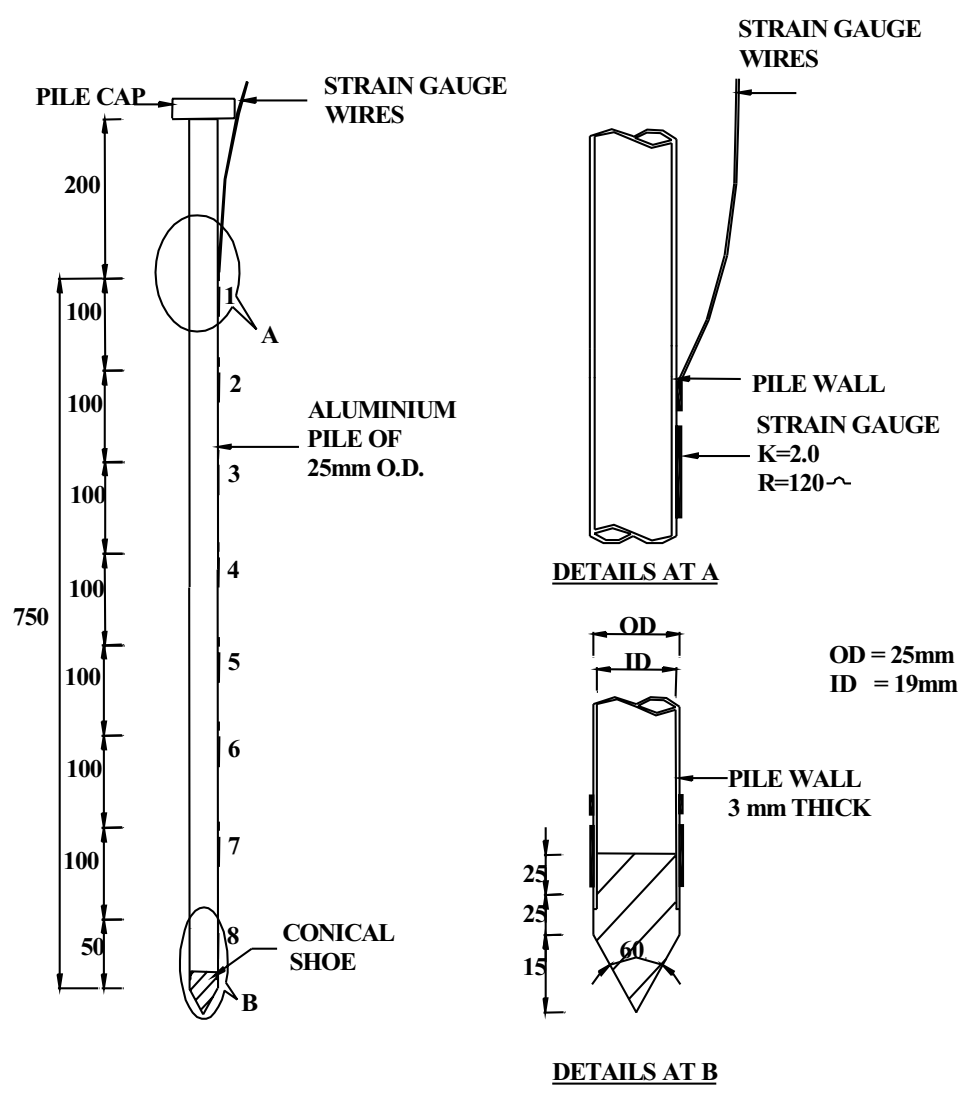

ALL DIMENSIONS ARE IN mm

Fig. 1. Instrumented model pile.

the driving of piles and to prevent soil plugging in the hollow piles. A pile cap having weight equal to $3.1 \mathrm{~N}$ was attached to the pile head mainly to simulate the static vertical load on piles and clear resonance of soil-pile system.

Piles were instrumented with the foil type electrical strain gauges having electrical resistance of $120 \pm 1.2 \Omega$ fixed in quarter bridge arrangement to study its bending behaviour. After strain gauges were fixed and connected to the wire, a rubber membrane was wound at the location of strain gauges and araldite solution was applied to make sure the strain gauges were waterproof. Figure 1 shows the instrumented model pile with details of conical shoe. The instrumented model pile was then calibrated to determine the relationship between the strain and bending moment at various locations of the strain gauges by a simple bending test with simply supported conditions.

\section{Horizontal vibration tests on piles}

\subsection{Elastic half space simulation}

Commonly adopted shapes of the test facility is square, rectangular or circular and the plan dimensions of the test facility must be greater than 10 times the diameter of the pile in the direction of loading for piles under static horizontal loads $[13,32]$. But in the case of dynamic loading, the reflection of vibration induced-stress waves from the rigid boundary wall is often observed, which interfere with the actual response of piles. Hence, it is very essential to curtail the reflection of stress waves or otherwise the wave reflection must be minimum when dynamic experiments are planned in the laboratory. Elastic Half Space Simulation (EHSS) was developed similar to the one 


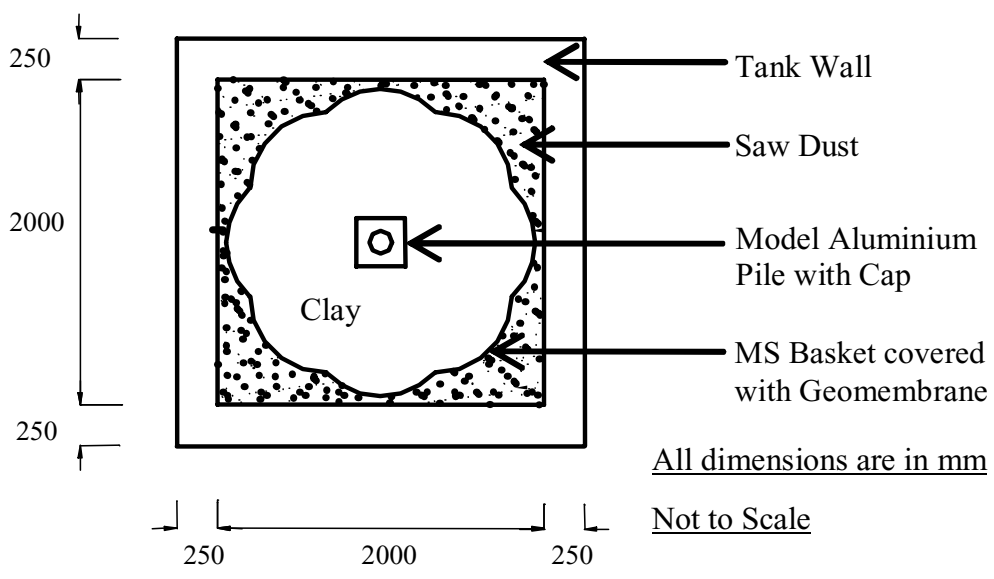

Fig. 2. Simulated elastic half space.

adopted by [14], which is shown in Fig. 2. EHSS consists of a test tank of size $2.0 \mathrm{~m} \times 2.0 \mathrm{~m} \times 1.5 \mathrm{~m}$, an absorbing layer of sawdust and a boundary element between them. The tank wall is made of hollow cement blocks of about $250 \mathrm{~mm}$ thickness. The boundary element consists of mild steel basket welded in logarithmic arc spiral shape, which is covered with the geomembrane sheet to separate the soil from the absorbing layer as well as to maintain constant moisture content in the clay layer. The geomembrane was made to the required logarithmic arc shape with the mild steel basket by hot air welding. After welding, fiberglass coating was applied to bond the mild steel basket with welded geomembrane and it is checked for water leakage.

\subsection{Dynamic loading and measurement of response}

The EHSS with Data Acquisition System used for conducting the horizontal vibration tests and for the measurement of response is shown in Fig. 3. A $100 \mathrm{~N}$-capacity electro-dynamic exciter fixed in the loading frame was attached to the pile cap such that it applies sinusoidal horizontal dynamic load $\left(\mathrm{F}_{0}\right)$ to the pile. The load transferred to the pile head was measured with the help of $2 \mathrm{kN}$-capacity HBM make load cell attached between the pile cap and exciter. HBM make LVDT attached on the pile cap was used to measure the time history of the pile head displacement $\left(\mathrm{A}_{0}\right)$. Instrumented pile measured the bending moment variation along the pile length due to horizontal dynamic load. A Data Acquisition System consisting of Pentium II PC with DAS card, DAS software "GeniDAQ" and HBM make MGC plus Multi-channel digital carrier frequency amplifier system was used to observe and measure the load transferred to the pile head, pile head displacement and strain along the pile length automatically. An AGILENT make digital storage oscilloscope was used to cross check the load and amplitude measurements.

\subsection{Dynamic properties of clay}

Clay was mixed with required amount of water to get the particular consistency index. Uniformly mixed clay was placed and hand-packed in the EHSS in several layers of $150 \mathrm{~mm}$ thickness and each layer was tamped with template so as to remove the entrapped air. Clay samples were collected from the test tank for confirming the homogeneity as adopted by [17]. Water content test was carried out collected soil samples and found that the water content is almost constant with depth as well as in the radial direction, which ensures the homogeneity of clay. The dynamic properties of clay were determined by conducting cross-hole tests in the EHSS filled with clay. The tests were conducted at various depths of $0.25 \mathrm{~m}, 0.50 \mathrm{~m}, 0.75 \mathrm{~m}$ and $1.00 \mathrm{~m}$ for all consistency indices of clay. From the cross-hole test data, the shear wave velocities at various depths of clay layer with different consistencies were determined. The measured shear wave velocity $\left(\mathrm{V}_{s}\right)$ is about $40 \mathrm{~m} / \mathrm{s}$ for very soft clay, but increases to $130 \mathrm{~m} / \mathrm{s}$ for medium stiff clay. The maximum shear modulus of clay $\left(\mathrm{G}_{s}\right)$ was estimated using the expression:

$$
G_{s}=\rho V_{s}^{2}
$$




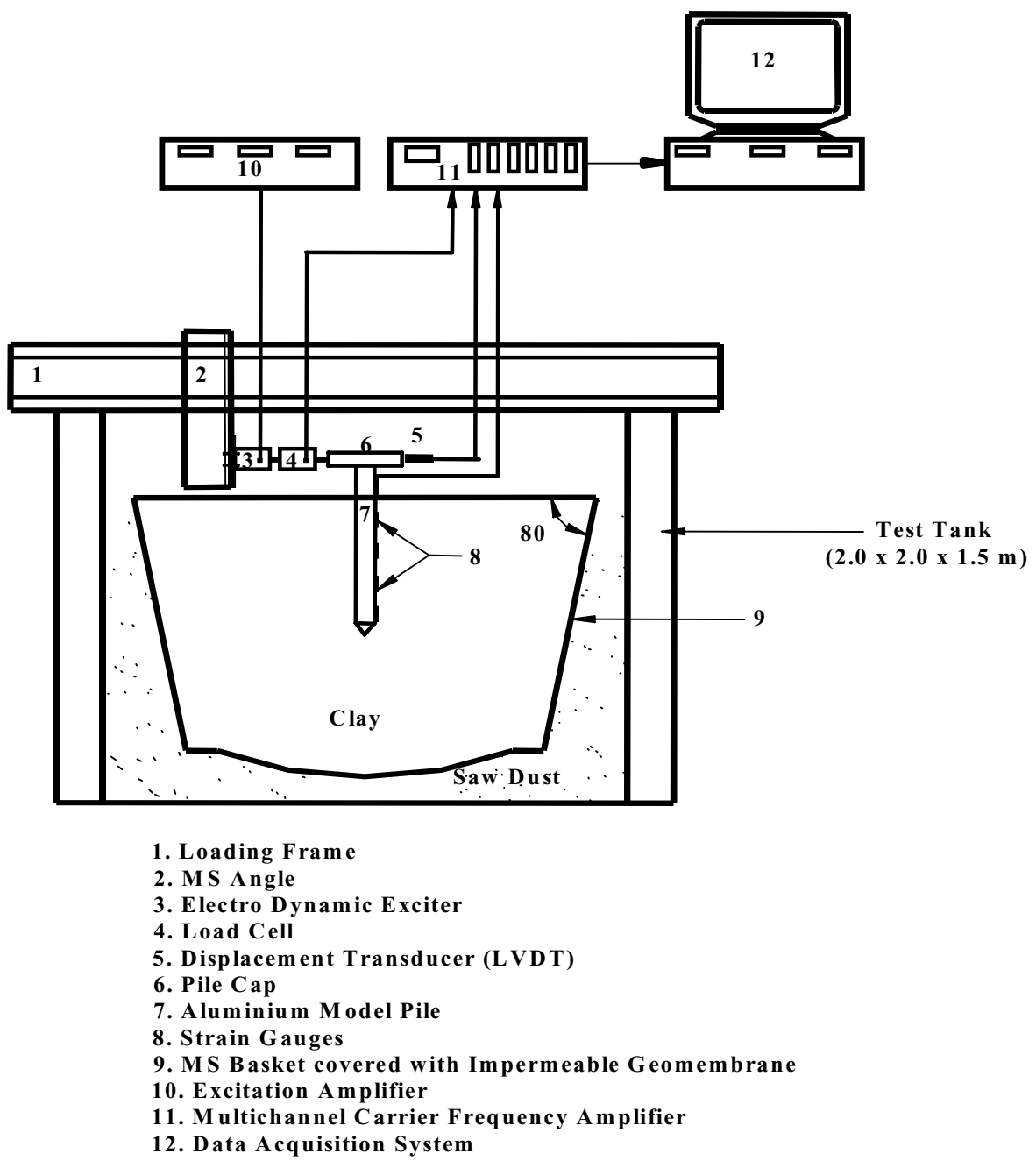

Fig. 3. Elastic half space test facility with DAS.

where $\rho=$ saturated density of soil, which was determined in-place of the tank by cylindrical barrel method. The variation of estimated values of maximum shear modulus $\left(\mathrm{G}_{s}\right)$ with depth for different consistencies of clay is shown in Fig. 4. It is clearly evident from Fig. 4 that, the maximum shear modulus of clay remains constant with depth of EHSS at all consistencies of clay.

\subsection{Test procedure}

The instrumented model pile was gently pushed vertically into the prepared clay bed and sufficient time was allowed for the soil to regain its original strength, based on its thixotropic nature. Preliminary tests were conducted on a pile having $\mathrm{L} / \mathrm{d}=20$ embedded in clay filled up in a rigid square tank and in the EHSS of same size. The sinusoidal horizontal dynamic load was applied to the pile head on piles embedded in rigid square tank and EHSS. The load transferred to the pile head $\left(\mathrm{F}_{0}\right)$, pile head displacement $\left(\mathrm{A}_{0}\right)$ and dynamic strain along the pile length were observed and measured using the Data Acquisition System. The observed response of pile in the rigid square tank and in the EHSS is given in Fig. 5. It is clearly evident from Fig. 5 that the response curve for the pile embedded in the rigid tank is scattered and multi-peaks are observed due to reflection of long period waves. But it is seen from Fig. 5 that the observed response curve for the pile embedded in the EHSS shows single peak that confirms the reflected stress waves, if any, do not interfere with the response of piles. The actual tests were conducted on 


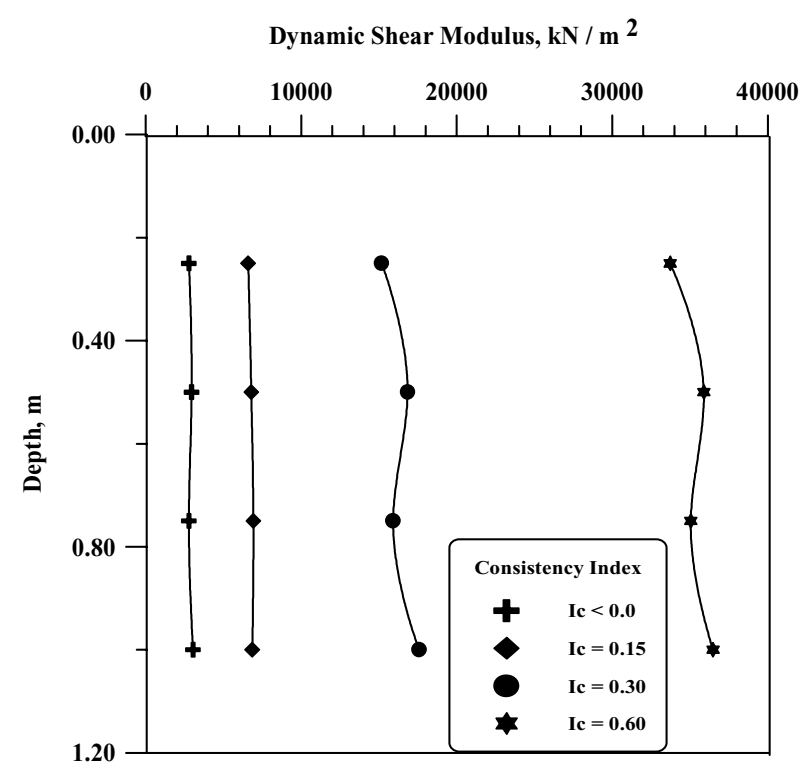

Fig. 4. Variation of dynamic shear modulus of clay with depth.

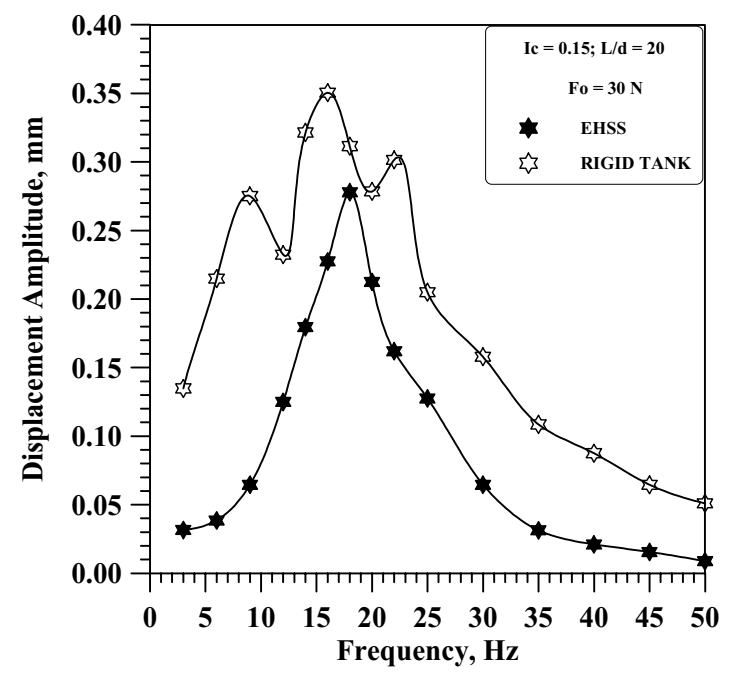

Fig. 5. Comparison of frequency response curve in rigid square tank and EHSS.

piles with length to diameter ratio (L/d) of 10, 20, 30 and 40. Piles were subjected to horizontal dynamic load with magnitudes $\left(\mathrm{F}_{0}\right)$ of $7 \mathrm{~N}, 14 \mathrm{~N}, 21 \mathrm{~N}$ and $30 \mathrm{~N}$ at wide range of frequency of excitation (f) from $2 \mathrm{~Hz}$ to $50 \mathrm{~Hz}$. The horizontal vibration tests were carried out on piles embedded in different consistencies of clay.

\section{Results and discussion}

\subsection{Horizontal vibration response}

A typical frequency response curve obtained from the observed time histories of displacement for the pile with $\mathrm{L} / \mathrm{d}=30$ embedded in soft clay (Consistency index, $\mathrm{I}_{c}=0.30$ ) is given in Fig. 6 . The figure clearly shows the 


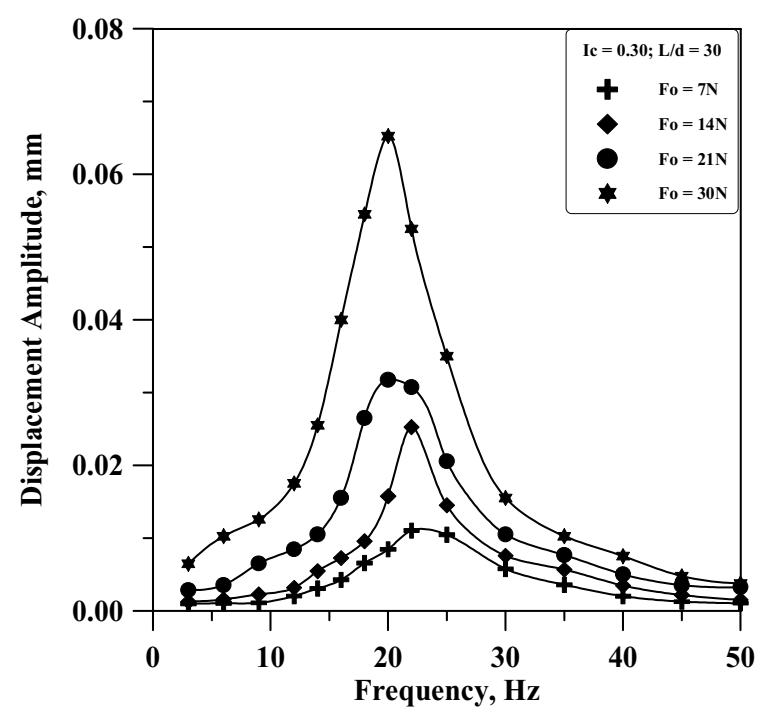

Fig. 6. Frequency response curve for $\mathrm{I}_{c}=0.30 ; \mathrm{L} / \mathrm{d}=30$.

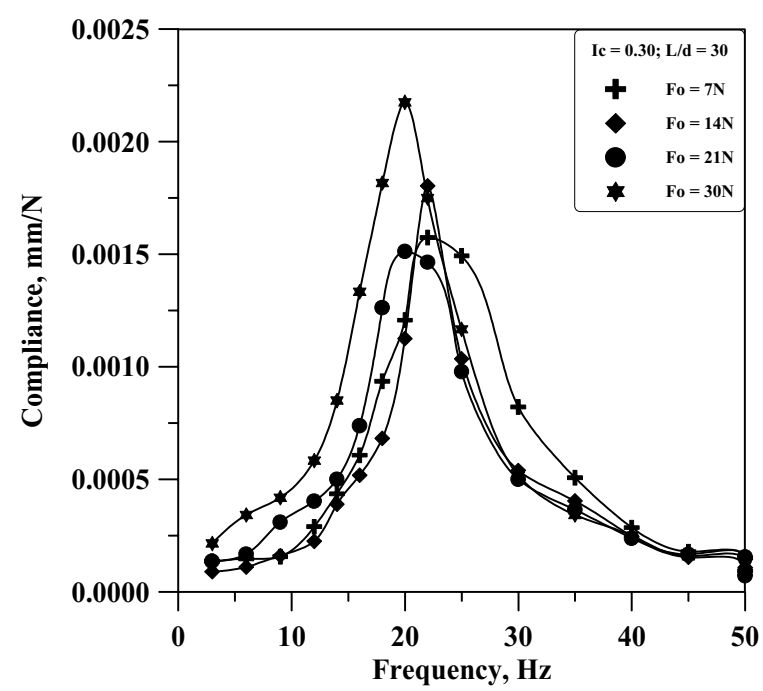

Fig. 7. Normalized frequency response curve for $\mathrm{I}_{c}=0.30 ; \mathrm{L} / \mathrm{d}=30$.

occurrence of single peak in the frequency response curves, which indicates that the soil-pile system behaves as a SDOF system. It is also depicted from the figure that the occurrence of peaks at different natural frequencies proves the prevalence of nonlinear response of the soil-pile system due to stiffness degradation. The compliance (i.e., the ratio of the displacement to the force applied or also known as inverse of stiffness) at all dynamic force values were calculated and a typical compliance versus frequency plot for the pile with $\mathrm{L} / \mathrm{d}=30$ embedded in soft clay $\left(\mathrm{I}_{c}=\right.$ 0.30) is shown in Fig. 7. For a typical linear system, the displacement is linearly proportional to the force and hence the variation of compliance with frequency at all forces must become a single curve. It is crystal clear from Fig. 7 that the occurrence of distinguishable compliance curves also proves the prevalence of nonlinear response of the soil-pile system particularly in the low frequency to resonance region. A similar finding was also reported based on the nonlinear spring-dashpot model [9]. However, it is observed from Fig. 8 (i.e., a plot of compliance versus frequency for the pile with $\mathrm{L} / \mathrm{d}=30$ embedded in medium stiff clay, $\mathrm{I}_{c}=0.60$ ) that compliance curves at all magnitudes of force tend to merge and the peaks occur more or less at single frequency which indicates the degree 
Table 2

Measured natural frequency of soil-pile system

\begin{tabular}{cccccc}
\hline Consistency & $\mathrm{L} / \mathrm{d}$ & \multicolumn{4}{c}{ Natural Frequency, Hz } \\
\cline { 3 - 6 } Index, $_{c}$ & Ratio & $\mathrm{F}_{0}=7 \mathrm{~N}$ & $\mathrm{~F}_{0}=14 \mathrm{~N}$ & $\mathrm{~F}_{0}=21 \mathrm{~N}$ & $\mathrm{~F}_{0}=30 \mathrm{~N}$ \\
\hline$\approx 0.0$ & 10 & 14.00 & 14.00 & 14.00 & 13.50 \\
& 20 & 14.00 & 14.00 & 13.75 & 13.50 \\
& 30 & 14.00 & 13.50 & 13.00 & 11.50 \\
0.15 & 40 & 16.00 & 14.75 & 14.00 & 13.00 \\
& 10 & 16.25 & 16.00 & 15.50 & 14.50 \\
& 20 & 18.25 & 17.90 & 17.75 & 17.50 \\
0.30 & 30 & 20.50 & 20.00 & 17.90 & 17.00 \\
& 40 & 24.75 & 22.20 & 21.80 & 20.00 \\
& 10 & 18.50 & 17.75 & 16.50 & 16.00 \\
& 20 & 21.00 & 20.00 & 19.50 & 18.25 \\
0.60 & 30 & 23.00 & 22.25 & 20.50 & 20.00 \\
& 40 & 26.75 & 25.25 & 24.75 & 22.25 \\
& 10 & 20.00 & 19.50 & 19.00 & 18.50 \\
& 20 & 22.00 & 22.00 & 21.00 & 20.50 \\
& 30 & 26.00 & 25.50 & 25.00 & 25.00 \\
& 40 & 30.00 & 30.00 & 29.50 & 29.00 \\
\hline
\end{tabular}

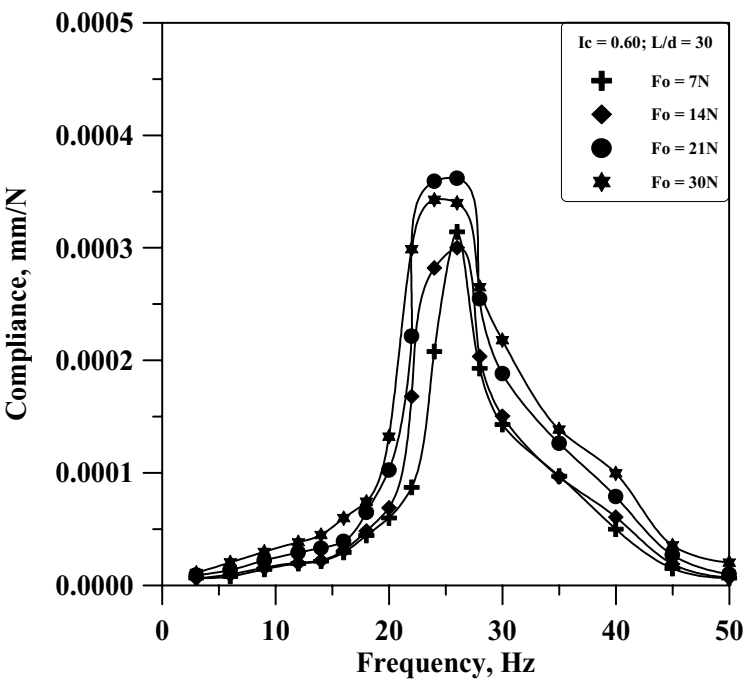

Fig. 8. Normalized frequency response curve for $\mathrm{I}_{c}=0.60 ; \mathrm{L} / \mathrm{d}=30$.

of nonlinearity reduces with an increase in the consistency of clay or stiffness of the system.

\subsection{Natural frequency}

The natural frequency $\left(f_{n}\right)$ of the soil-pile system obtained from the frequency response curves is given in Table 2 . It can be seen from the table that the natural frequency of all piles embedded at various consistencies of clay varies from 11.5 to $30.0 \mathrm{~Hz}$. It can also be depicted from the table that the measured natural frequency of the soil-pile system ranges from 29 to $30 \mathrm{~Hz}$ for the pile with $\mathrm{L} / \mathrm{d}=40$, embedded in medium stiff clay $\left(\mathrm{I}_{c}=0.60\right)$. The natural frequency of full-scale soil-pile system measured by Puri and Prakash [16] ranges from $27.5 \mathrm{~Hz}$ to $34 \mathrm{~Hz}$, for the pile with $\mathrm{L} / \mathrm{d}=42$ embedded in stiff clay. This indicates that the natural frequencies obtained from the experiments conducted on model piles closely simulate the field conditions. It can also be found from Table 2 that the natural frequency increases with an increase in the embedded pile length and consistency of clay due to the increase in the overall stiffness of the soil-pile system. The typical variation of measured natural frequency $\left(\mathrm{f}_{n}\right)$ with the pile length for piles embedded in soft clay $\left(\mathrm{I}_{c}=0.30\right)$ is shown in Fig. 9. It is clearly observed from Fig. 9 that the natural 


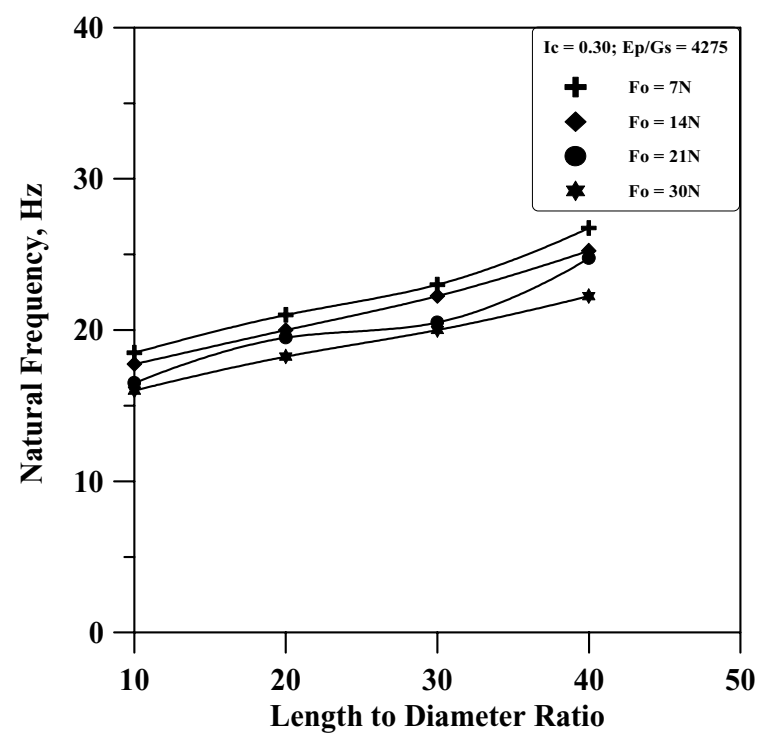

Fig. 9. Variation of natural frequency with pile length.

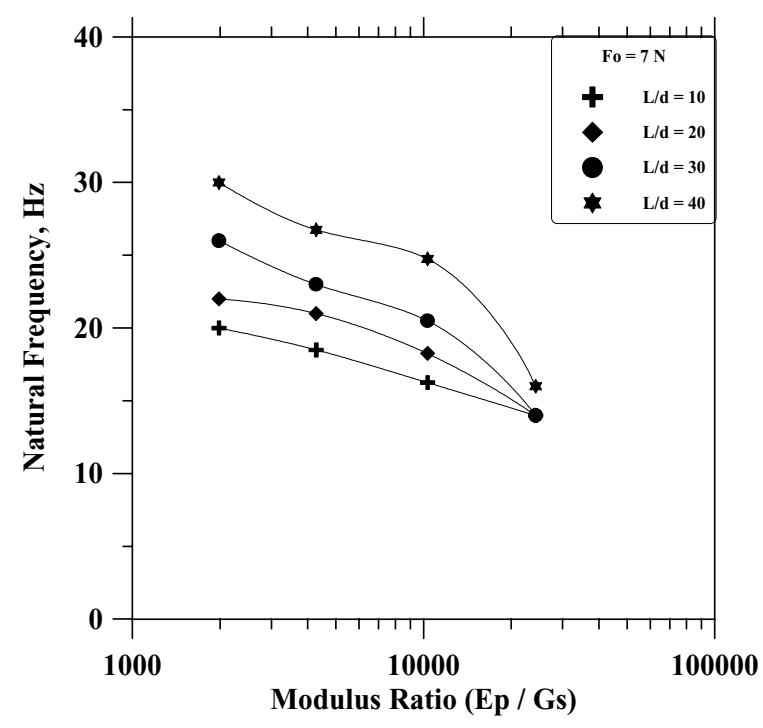

Fig. 10. Variation of natural frequency with modulus ratio.

frequency of soil-pile system increases linearly with the pile length at all force levels. It is mainly due to an increase of stiffness of the soil-pile system with an increase in the pile length deriving from an increase of passive resistance of soil. Also, it is evident from Fig. 9 that slight reduction in the natural frequency with an increase of force level $\left(\mathrm{F}_{o}=21 \mathrm{~N}\right.$ and $\left.30 \mathrm{~N}\right)$, which is mainly due to stiffness degradation at higher strain because of nonlinear behaviour and hysteretic damping.

The variation of natural frequency with modulus ratio for different pile lengths is shown in Fig. 10. The modulus ratio, $\mathrm{E}_{p} / \mathrm{G}_{s}$, is the ratio of the Young's modulus of pile $\left(\mathrm{E}_{p}\right)$ to the low-strain shear modulus of clay $\left(\mathrm{G}_{s}\right)$. A high modulus ratio represents a very low shear modulus for the clay, i.e., very soft clay and vice versa. It can be noticed from Fig. 10 that at high modulus ratio (i.e., very soft clay), the natural frequency of soil-pile system is practically same irrespective of the pile length due to the stiffness degradation resulting from the strong nonlinear behaviour at very soft consistency of the clay. However, the natural frequency increases significantly with the increase in 
Table 3

Measured peak amplitude of soil-pile system

\begin{tabular}{|c|c|c|c|c|c|}
\hline \multirow{2}{*}{$\begin{array}{l}\text { Consistency } \\
\text { Index, } \mathrm{I}_{c}\end{array}$} & \multirow{2}{*}{$\begin{array}{c}\mathrm{L} / \mathrm{d} \\
\text { Ratio }\end{array}$} & \multicolumn{4}{|c|}{ Peak Amplitude, mm } \\
\hline & & $\mathrm{F}_{0}=7 \mathrm{~N}$ & $\mathrm{~F}_{0}=14 \mathrm{~N}$ & $\mathrm{~F}_{0}=21 \mathrm{~N}$ & $\mathrm{~F}_{0}=30 \mathrm{~N}$ \\
\hline \multirow[t]{4}{*}{$\approx 0.0$} & 10 & 1.920 & 2.716 & 3.645 & 4.950 \\
\hline & 20 & 1.652 & 2.215 & 3.020 & 4.135 \\
\hline & 30 & 1.64 & 1.850 & 2.812 & 3.871 \\
\hline & 40 & 0.965 & 1.341 & 2.104 & 3.175 \\
\hline \multirow[t]{4}{*}{0.15} & 10 & 0.108 & 0.183 & 0.271 & 0.346 \\
\hline & 20 & 0.084 & 0.152 & 0.196 & 0.278 \\
\hline & 30 & 0.067 & 0.108 & 0.149 & 0.217 \\
\hline & 40 & 0.046 & 0.076 & 0.124 & 0.164 \\
\hline \multirow[t]{4}{*}{0.30} & 10 & 0.018 & 0.042 & 0.073 & 0.112 \\
\hline & 20 & 0.014 & 0.030 & 0.048 & 0.082 \\
\hline & 30 & 0.011 & 0.025 & 0.032 & 0.065 \\
\hline & 40 & 0.009 & 0.016 & 0.024 & 0.048 \\
\hline \multirow[t]{4}{*}{0.60} & 10 & 0.0032 & 0.0090 & 0.0146 & 0.0249 \\
\hline & 20 & 0.0028 & 0.0066 & 0.0114 & 0.0165 \\
\hline & 30 & 0.0022 & 0.0042 & 0.0076 & 0.0102 \\
\hline & 40 & 0.0018 & 0.0031 & 0.0052 & 0.0072 \\
\hline
\end{tabular}

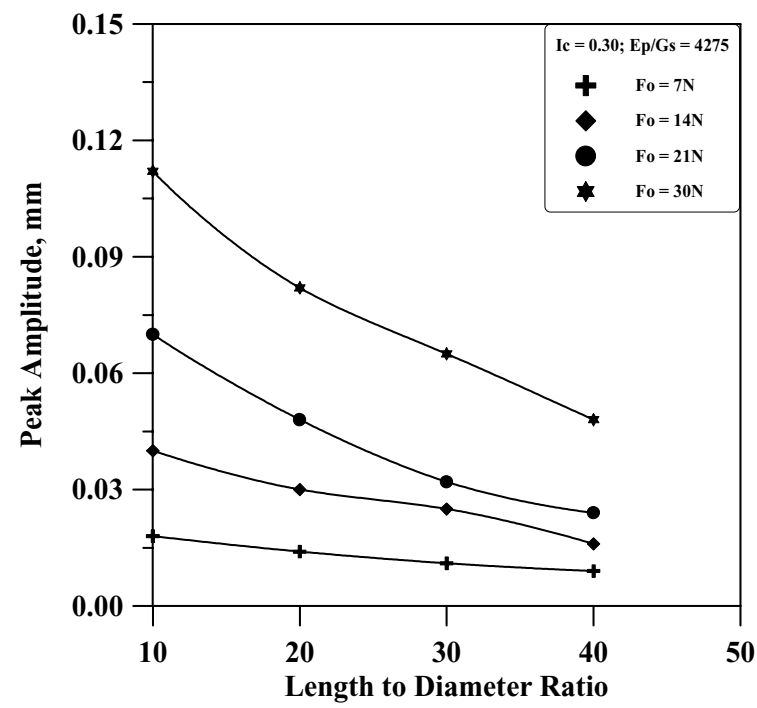

Fig. 11. Variation of peak amplitude with pile length.

consistency of the clay, which is attributed to the higher stiffness of clay. Furthermore, the degree of nonlinearity is relatively low for piles embedded in medium stiff clay that leads to a least degradation of stiffness.

\subsection{Peak amplitude}

The peak amplitude $\left(\mathrm{A}_{0 \max }\right)$ corresponding to the natural frequency was obtained from the frequency response curves and presented in Table 3. It is found from the table that the peak amplitude of vibration varies in the range, $0.002 \mathrm{~mm}$ to $4.95 \mathrm{~mm}$. It is also observed from the table that the peak amplitude of soil-pile system reduces by about $35 \%$ to $70 \%$ with the increase in the pile length at all magnitudes of dynamic forces for different consistency indices of clay. This can be attributed to the dissipation of energy through passage or radiation of waves, called as radiation or geometrical damping, which increases with the increase in the pile length. A typical variation of measured peak amplitude with the pile length for piles embedded in soft clay $\left(\mathrm{I}_{c}=0.30\right)$ is shown in Fig. 11. It could be inferred from Fig. 11 that the peak amplitude reduces with the increase in the pile length at all magnitude of applied lateral force. The reduction in the peak amplitude with an increase in the pile length is less significant at low magnitude of 


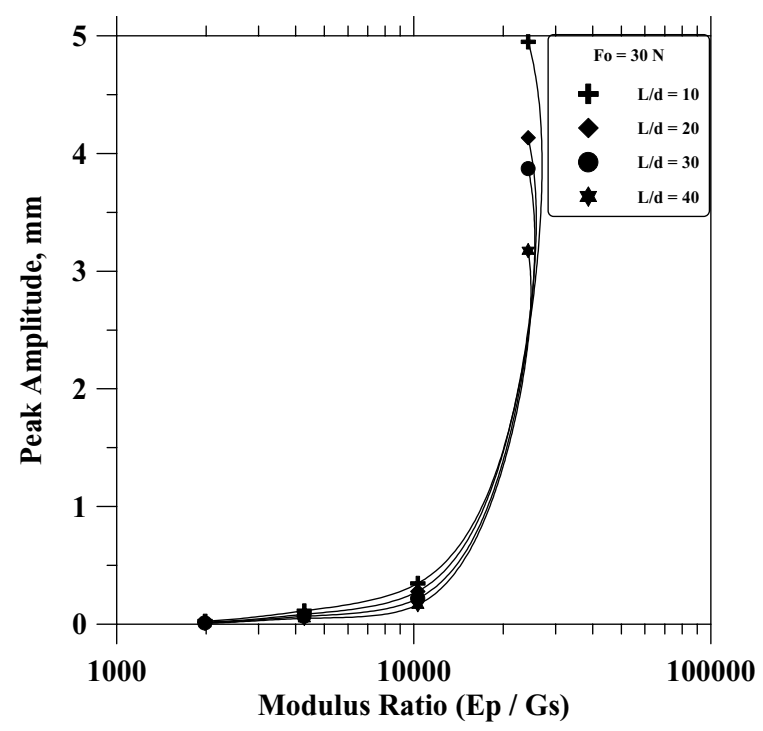

Fig. 12. Variation of peak amplitude of piles with modulus ratio at $\mathrm{F}_{o}=30 \mathrm{~N}$.

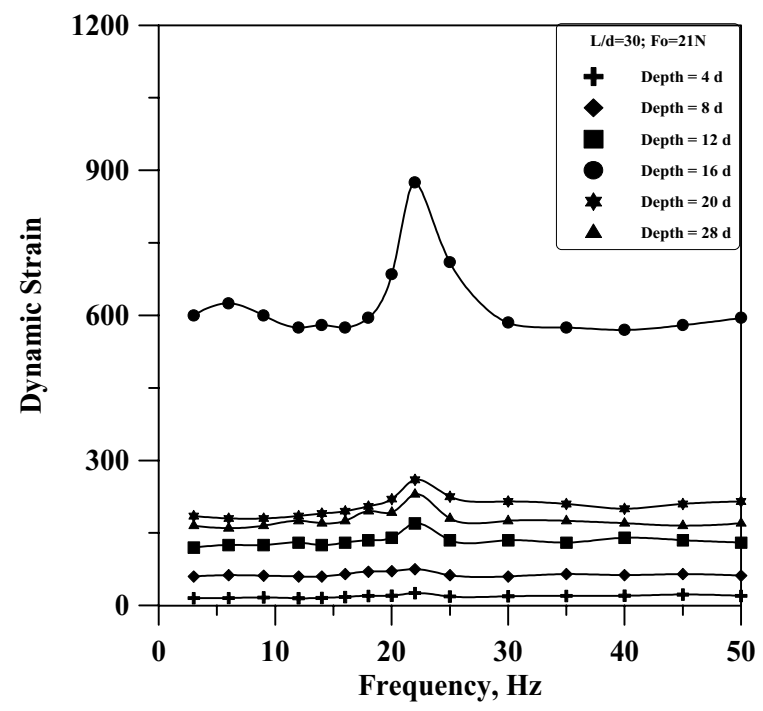

Fig. 13. Variation of dynamic strain with frequency for $\mathrm{I}_{c}=0.30 ; \mathrm{L} / \mathrm{d}=30$.

dynamic force $\left(\mathrm{F}_{o}=7 \mathrm{~N}\right.$ and $\left.14 \mathrm{~N}\right)$ due to the presence of only geometrical damping. However, the peak amplitude reduces significantly by about $60 \%$ with an increase in the pile length at relatively high magnitude of dynamic force $\left(\mathrm{F}_{o}=21 \mathrm{~N}\right.$ and $\left.30 \mathrm{~N}\right)$ due to the combination of both geometrical and hysteretic damping of soil-pile system.

The variation of peak amplitude $\left(\mathrm{A}_{0 \max }\right)$ with modulus ratio $\left(\mathrm{E}_{p} / \mathrm{G}_{s}\right)$ for different pile lengths is shown in Fig. 12 . It can be found from Fig. 12 that a drastic reduction in the peak amplitude with the increase in the shear modulus of clay and magnitude of dynamic load at medium stiff clay. This is attributed to the combined effect of the increase in stiffness and damping of the clay. It can be concluded here that just by altering the consistency of the clay in the field to a small extent, a significant reduction in the peak amplitude can be achieved. It can also be inferred from Fig. 12 that at high modulus ratio $\left(\mathrm{E}_{p} / \mathrm{G}_{s}\right)$, i.e., for piles embedded in very soft consistency of clay, reduction of peak amplitude with the pile length is significant due to the occurrence of large hysteretic damping resulting from strong nonlinear behaviour of soft clay. 


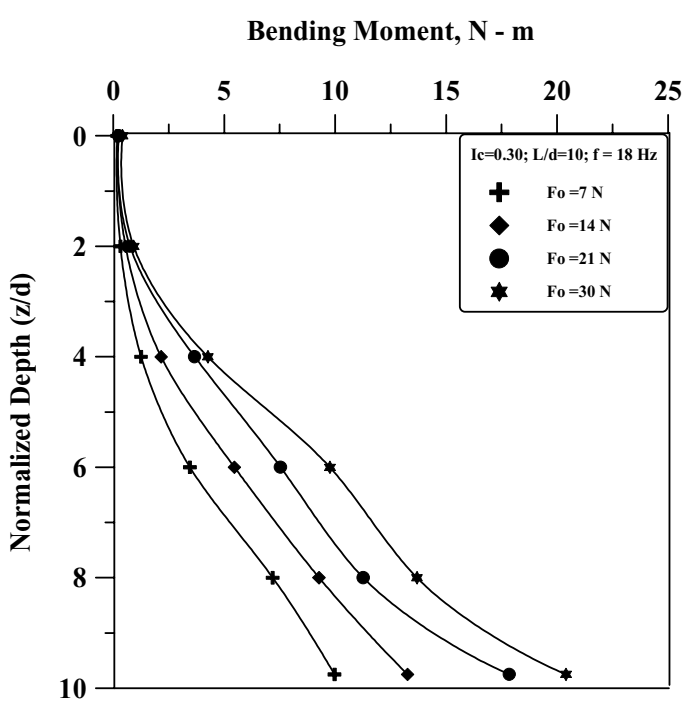

(a)

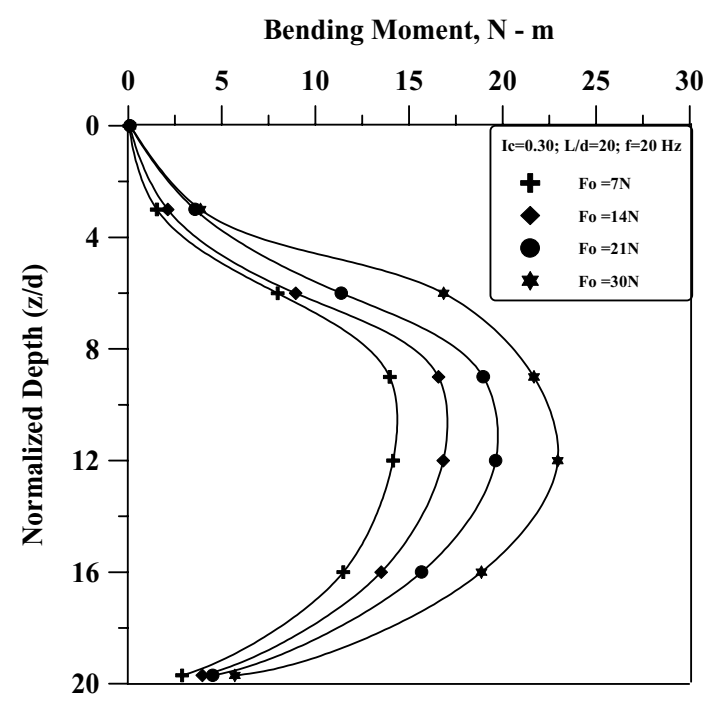

(b)

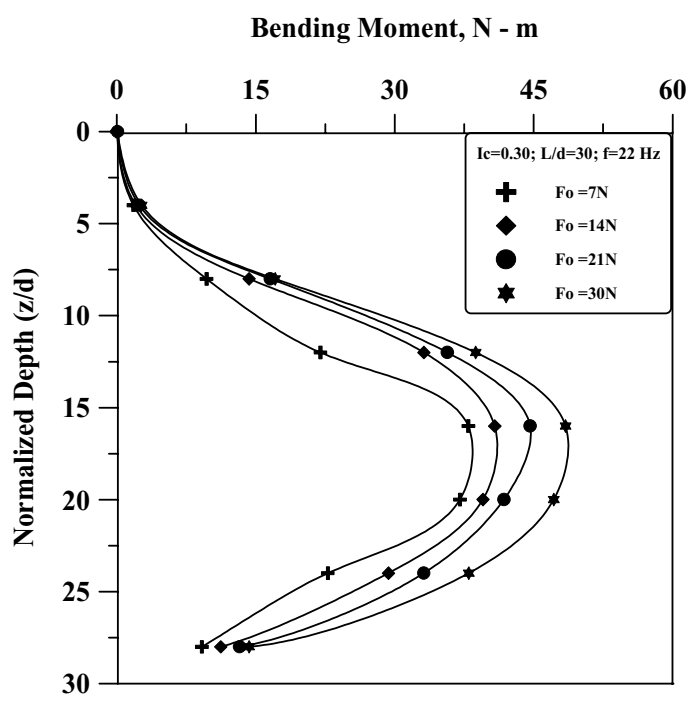

(c)

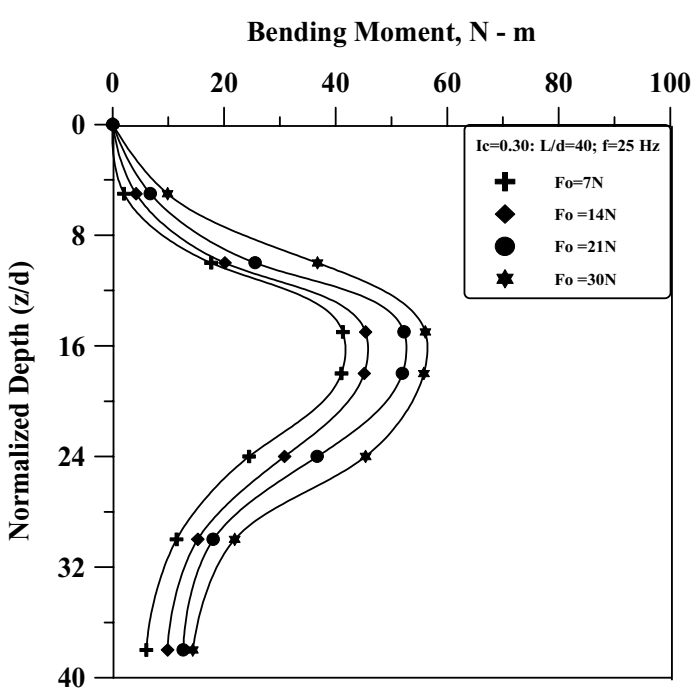

(d)

Fig. 14. Variation of dynamic bending moment of piles with normalized depth for $\mathrm{L}=0.30$ (a) $\mathrm{L} / \mathrm{d}=10$; (b) $\mathrm{L} / \mathrm{d}=20$; (c) $\mathrm{L} / \mathrm{d}=30$ (d) $\mathrm{L} / \mathrm{d}=$ 40.

\subsection{Bending moment}

\subsubsection{Dynamic Strain vs. Frequency}

A typical plot of dynamic strain versus frequency (f) at different location of the pile length for piles embedded in soft clay $\left(\mathrm{I}_{c}=0.30\right)$ is given in Fig. 13. It is observed from Fig. 13 that the maximum dynamic strain occurs at the natural frequency $\left(\mathrm{f}_{n}\right)$ of the soil-pile system. This is mainly due to large inertial force mobilized near the resonance region because of large amplitude of vibration. It could also be noted from Fig. 13 that the frequency dependency of dynamic strain or BM is more predominant in the most adverse location of the maximum bending moment. Similar findings have also been reported that the maximum dynamic bending moment occurs at the fundamental frequency of the system based on the Beam-on-Dynamic Winkler Formulation [18]. The dynamic bending moment $\left(\mathrm{M}_{d}\right)$ was 


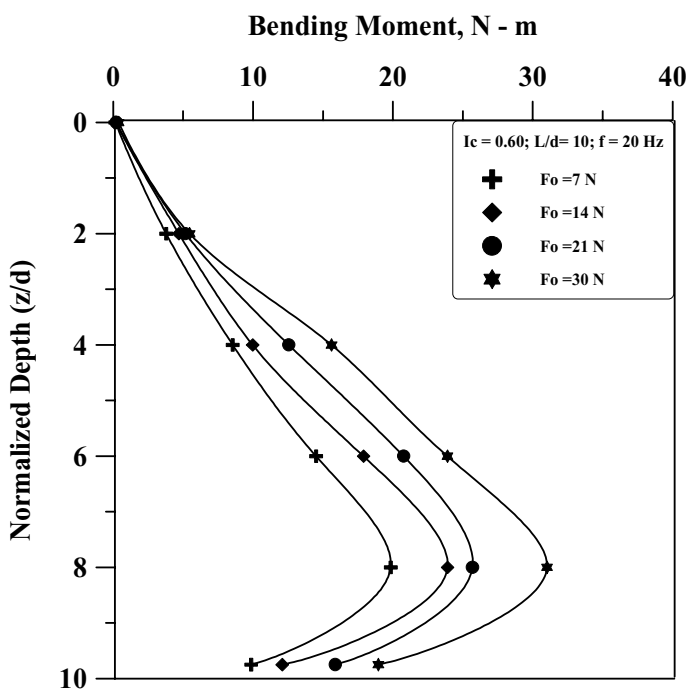

(a)

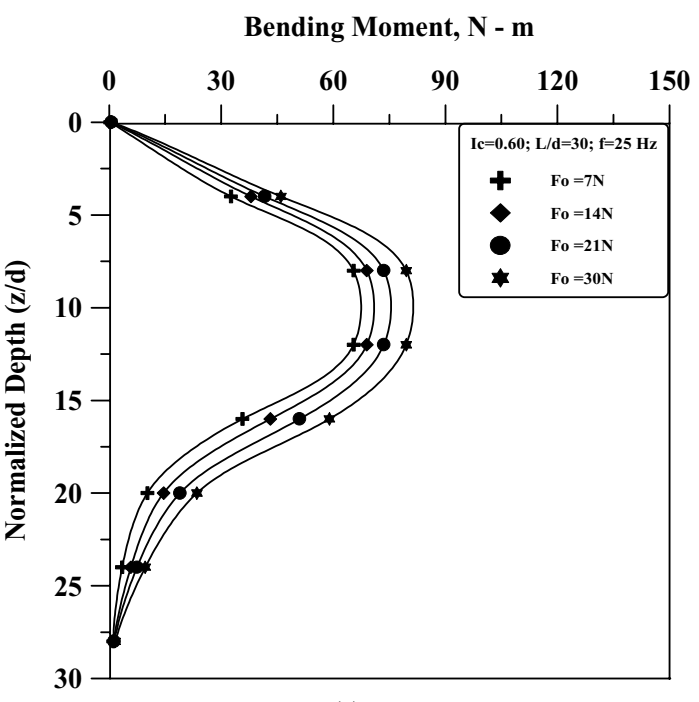

(c)

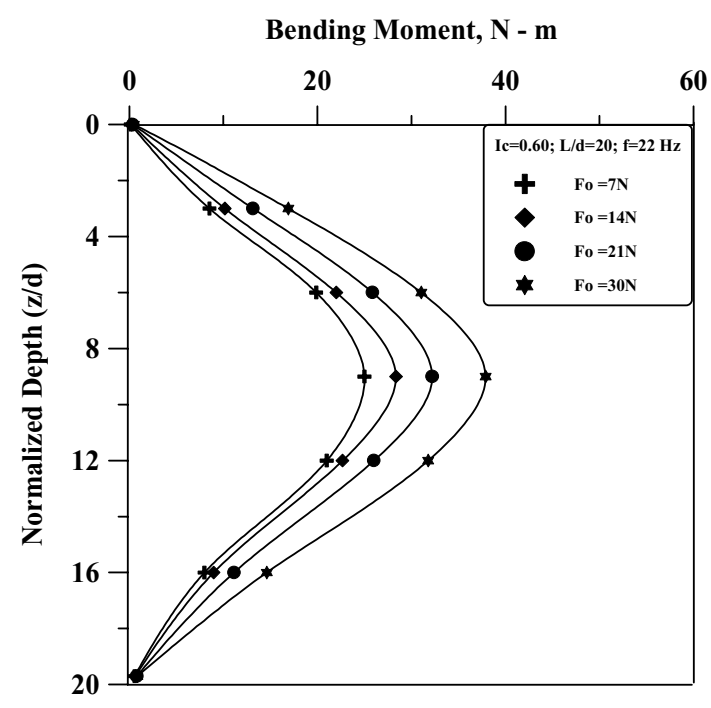

(b)
60

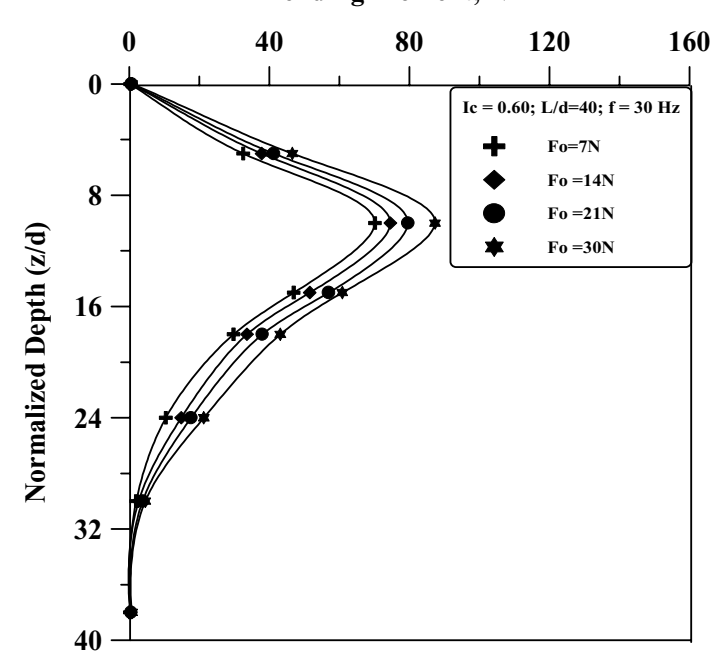

(d)

Fig. 15. Variation of dynamic bending moment of piles with normalized depth for $\mathrm{E}=0.60$ (a) $\mathrm{L} / \mathrm{d}=10$; (b) $\mathrm{L} / \mathrm{d}=20$; (c) $\mathrm{L} / \mathrm{d}=30$ (d) $\mathrm{L} / \mathrm{d}=$ 40 .

obtained from the measured peak strain at the natural frequency of the soil-pile system by multiplying the calibration factor obtained from the calibration test conducted on the instrumented model pile.

\subsubsection{Bending moment profile}

The variation of dynamic bending moment $\left(\mathrm{M}_{d}\right)$ with normalized depth $(\mathrm{z} / \mathrm{d})$ for piles embedded in soft clay $\left(\mathrm{I}_{c}\right.$ $=0.30$ ) is shown in Fig. 14. From Fig. 14, it is also noticed that, the bending moment even near the pile tip does not reach zero. This indicates that even the lower parts of the pile affect the pile head response to the inertia loads applied at the pile head. It is depicted from Fig. 14(a) that the pile with $\mathrm{L} / \mathrm{d}=10$ does not attain maximum dynamic bending moment, which assures the pile behaves as a short rigid pile. But, from Fig. 14(b) to d, it is observed that piles of $\mathrm{L} / \mathrm{d}=20,30 \& 40$ attain maximum dynamic bending moment at a depth of about 11 to 17 times diameter of the pile. However, it is seen from Fig. 15(a) that even for a pile with L/d = 10 embedded in medium stiff clay $\left(\mathrm{I}_{c}=0.60\right)$, the maximum bending moment occurs at relatively shallow depth. For piles with L/d $\geqslant 20$ (Figs $15 \mathrm{~b}$ to 
Table 4

Measured depth of maximum dynamic BM

\begin{tabular}{ccccc}
\hline Consistency & \multicolumn{4}{c}{ Depth of Max. Dynamic BM } \\
\cline { 2 - 5 } Index, $_{c}$ & $\mathrm{~L} / \mathrm{d}=10$ & $\mathrm{~L} / \mathrm{d}=20$ & $\mathrm{~L} / \mathrm{d}=30$ & $\mathrm{~L} / \mathrm{d}=40$ \\
\hline$\approx 0.0$ & $10 \mathrm{~d}$ & $19.7 \mathrm{~d}$ & $20 \mathrm{~d}$ & $24 \mathrm{~d}$ \\
0.15 & $10 \mathrm{~d}$ & $12 \mathrm{~d}$ & $18 \mathrm{~d}$ & $19 \mathrm{~d}$ \\
0.3 & $10 \mathrm{~d}$ & $11 \mathrm{~d}$ & $16 \mathrm{~d}$ & $17 \mathrm{~d}$ \\
0.6 & $8 \mathrm{~d}$ & $9 \mathrm{~d}$ & $10 \mathrm{~d}$ & $10 \mathrm{~d}$ \\
\hline
\end{tabular}

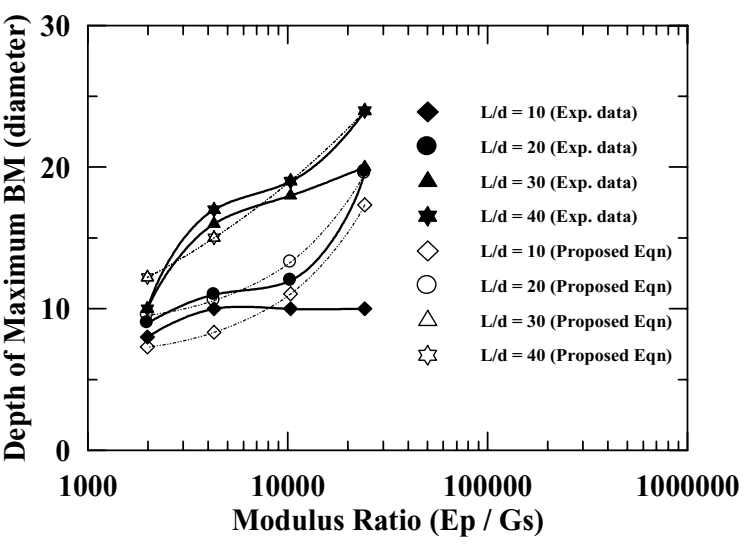

Fig. 16. Comparison the measured and predicted (using proposed equations) depth of maximum dynamic BM.

d) embedded in medium stiff clay, the bending moment reaches close to zero value at either near or well above the pile tip. This demonstrates that the active pile length reduces with an increase in the modulus of clay due to large stiffness of the clay that constraints the pile vibration.

\subsubsection{Depth of maximum bending moment}

For all piles embedded at various consistencies of clay, the measured depth of maximum dynamic bending moment $\left(z_{m d}\right)$ is presented in Table 4 and it is seen from the table that depth of maximum dynamic bending moment varies from 6 to 24 times the pile diameter. But the depth of maximum static bending moment $\left(z_{m s}\right)$ estimated by the method proposed by Broms [6] varies from 3 to 15 times diameter for different consistencies of clay, which indicates that the maximum dynamic bending moment $\left(\mathbf{M}_{d \max }\right)$ occurs at much deeper depth than the depth of maximum static bending moment. This shows that the active pile length increases under dynamic loads. It can also be concluded here that many piles, which exhibit a flexible (length-independent) static behaviour cannot be considered as flexible under dynamic loads at frequencies near resonance. This is mainly because of large inertial components mobilized under dynamic loads that need to be transferred to deeper depth, which necessitates the requirement of additional pile length under dynamic loads. Based on the experiments conducted in the laboratory [12] and field [41], similar conclusion was arrived for piles subjected to harmonic horizontal vibration. Finite element analysis [5,26] carried out on the piles subjected to static and dynamic horizontal loads also leads to the similar conclusion that the active length of piles increase under dynamic lateral loads.

Based on the results of the extensive laboratory experiments conducted as a part the present investigation, the following empirical equations are proposed for the estimation of the depth of maximum dynamic bending moment $\left(z_{m d}\right)$ by multi-regression analysis [42]:

$$
\text { For } \begin{aligned}
L / d<30, \quad \frac{z_{m d}}{d}= & 4.5 \times 10^{-4}\left(\frac{E_{p}}{G_{s}}\right) \\
& +0.225\left(\frac{L}{d}\right)+4.1634
\end{aligned}
$$




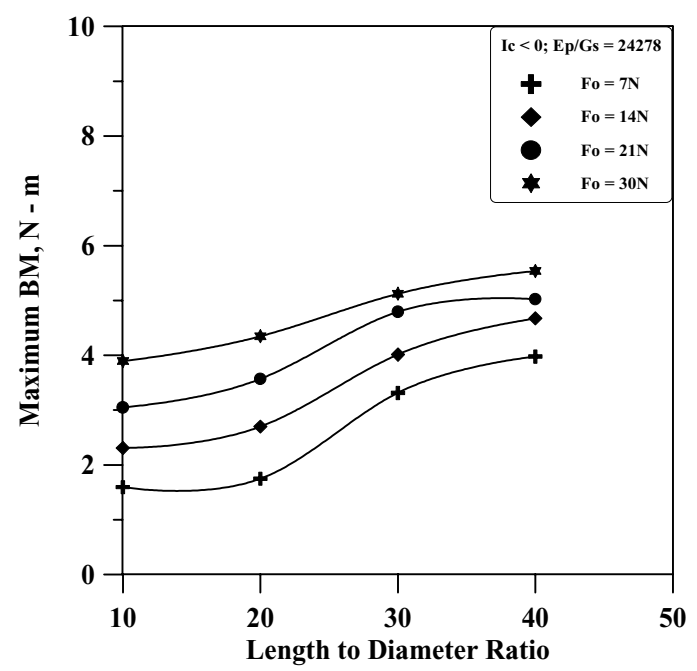

(a)

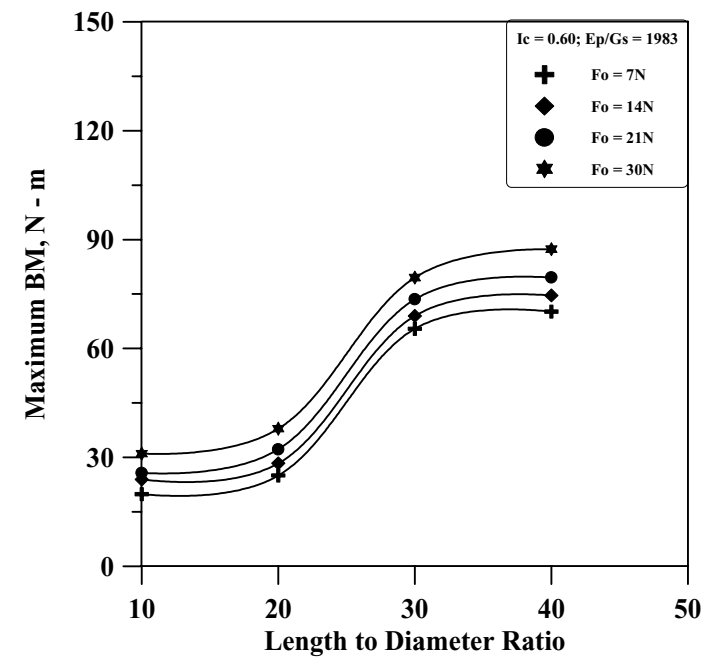

(b)

Fig. 17. Variation of maximum dynamic $\mathrm{BM}$ of piles with pile length at (a) $\mathrm{I}_{c} \approx 0.0$ (b) $\mathrm{I}_{c}=0.60$ ).

$$
\text { For } L / d \geqslant 30, \frac{z_{m d}}{d}=1.584\left(\frac{E_{p}}{G_{s}}\right)^{0.269}
$$

where $z_{m d}$ is the depth of maximum dynamic bending moment, $d$ is the pile diameter, $\mathrm{E}_{p}$ is the Young's modulus of pile material, $G_{s}$ is the low-strain shear modulus of clay and $\mathrm{L}$ is the pile length. The regression coefficient $\left(\mathrm{R}^{2}\right)$ of 0.8271 was obtained for the above equations. The above-proposed equations can be used to estimate the minimum pile length required under horizontal dynamic loads. The estimated depth of maximum dynamic bending moment using the above equations and the experimentally measured one are compared and shown in Fig. 16. It is seen from the figure that the proposed equations predict the depth of maximum bending moment with a fair accuracy for long piles embedded in all consistencies of clay, and for short piles in medium stiff clay only. But for very short piles in very soft clay, the proposed equation predicts the depth of maximum bending moment with the error, more than $70 \%$.

In view of the fact that the results obtained from the experimental studies on piles embedded in clay at low effective confining pressures, the proposed empirical equations may be verified further and modified accordingly as and when 


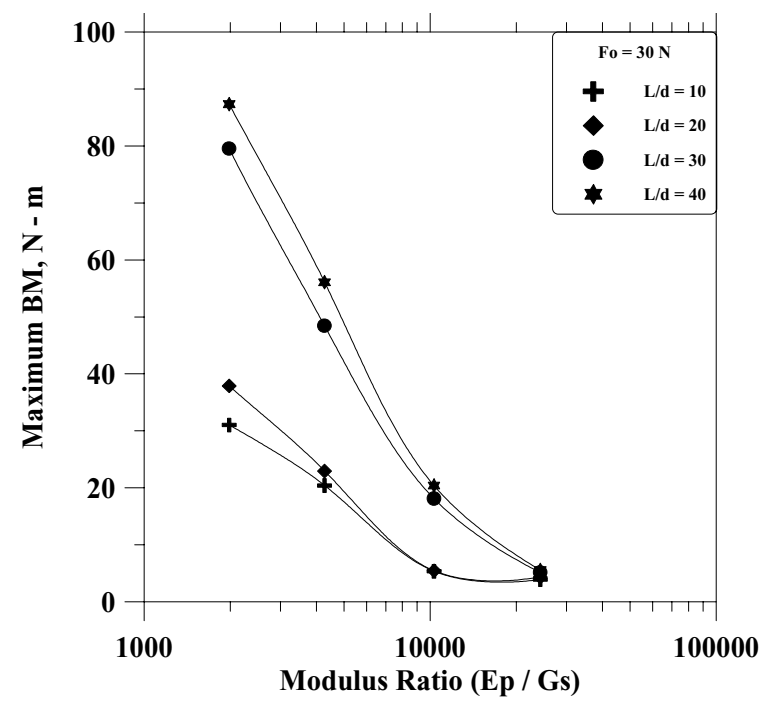

Fig. 18. Variation of maximum dynamic $\mathrm{BM}$ of piles with modulus ratio at $\mathrm{F}_{0}=30 \mathrm{~N}$.

a more reliable data made available based on either the centrifuge or full-scale experiments on instrumented piles, which represents the field stress conditions.

\subsubsection{Maximum bending moment}

The maximum dynamic bending moment $\left(\mathrm{M}_{d \max }\right)$ obtained from the bending moment profile for all piles at consistencies of clay ( $I_{c}=0.0$ and 0.60 ) is presented in Fig. 17. It can be easily depicted from the Fig. 17(a) that for piles embedded in very soft clay, the maximum dynamic bending moment increases almost linearly with an increase in the pile length (L/d ratio) and magnitudes of dynamic load $\left(\mathrm{F}_{0}\right)$. But, it can be depicted from Fig. 17(b) that the bending moment of long piles ( $\mathrm{L} / \mathrm{d}=30$ and 40 ) increases drastically due to increase of passive resistance of clay which restraints the pile movement against vibration and increase of effective pile length. It can be also noticed from Fig. 17(b) that the increase of maximum dynamic bending moment in proportion to the magnitude of dynamic load is hidden by the effect of passive resistance of clay with the increase in consistency to medium stiff state, which increases consequently the maximum dynamic bending moment. The variation of maximum dynamic bending moment with modulus ratio is presented in Fig. 18. It is observed from the figure that the maximum dynamic bending moment increases significantly by about 5 times for short piles $(\mathrm{L} / \mathrm{d} \leqslant 20)$ with a reduction of modulus ratio, i.e., with the increase in the shear modulus of clay. But, for long piles $(\mathrm{L} / \mathrm{d}>25)$ maximum dynamic bending moment increases drastically by about 10 to 12 times with the increase in the shear modulus of clay due to high stiffness and large passive resistance of soil that constraint the pile movement. It is noticed from Fig. 18 that the maximum dynamic bending moment is practically same irrespective of the pile length at very soft consistency of clay, since the passive resistance is much lower at low shear modulus. However at relatively high shear modulus, it is observed from the figure that the maximum dynamic bending moment of long flexible piles is by about 2 to 4 times higher than that of short rigid piles.

\section{Summary and conclusions}

Horizontal vibration tests were conducted on model piles embedded in different consistencies of clay in the simulated elastic half space. The response of the soil-pile system was observed and measured using a Data Acquisition System and the measured data were interpreted. It is found that the pile length, shear modulus of clay and magnitude of the applied force significantly influences the natural frequency of the soil-pile system. Natural frequency substantially increases with the increase in the pile length and shear modulus of clay at low magnitude of the dynamic force due to high stiffness of soil-pile system derived from passive resistance and inertia effect of the 
soil-pile system. However, the rate of increase of natural frequency significantly reduces at high magnitude of the dynamic force due to nonlinear behaviour of soil. The peak amplitude of piles reduces with the increase in the pile length and shear modulus of clay due to increase of geometrical and hysteretic damping. At low shear modulus of clay, the rate of reduction of peak amplitude increases significantly due to additional hysteretic damping resulting from strong nonlinear behaviour of clay at very soft consistency.

The maximum bending moment of piles occurs at the fundamental frequency of soil-pile system. The maximum dynamic bending moment for flexible piles is about 2 to 4 times higher than that of rigid piles. The bending moment under dynamic loads occurs at a depth of about 1.5 to 3.0 times than under static conditions, which indicates the increase of active pile length under dynamic loads. It can also be concluded here that many piles, which exhibit a flexible (length-independent) static behaviour cannot be considered as flexible under dynamic loads at frequencies near resonance and thus necessitate the requirement of additional pile length under dynamic loads applied at frequencies near resonance. The maximum dynamic BM of rigid piles increases about 5 times with increase of shear modulus, but for flexible piles the increase is about 11 times. Based on the results of the extensive laboratory experiments, empirical equations are proposed for the estimation of the depth of maximum dynamic bending moment and thereby the active pile length under horizontal dynamic loads. Since the horizontal vibrations tests have been carried out at relatively low effective confining pressure, the above findings may be verified further by carrying out in-situ horizontal vibration tests on fully instrumented piles.

\section{Notations}

$\mathrm{A}_{0}$ Dynamic amplitude, $\mathrm{mm}$

$\mathrm{A}_{0 \max }$ Peak amplitude corresponds to natural frequency, mm

d Diameter of pile, $\mathrm{mm}$

$\mathrm{E}_{p}$ Young's modulus of pile material, $\mathrm{kN} / \mathrm{m}^{2}$

$\mathrm{F}_{0}$ Magnitude of dynamic load, $\mathrm{N}$

f Frequency of excitation, $\mathrm{Hz}$

$\mathrm{f}_{n}$ Natural frequency of soil-pile system, $\mathrm{Hz}$

$\mathrm{G}_{s}$ Low-strain dynamic shear modulus of soil, $\mathrm{kN} / \mathrm{m}^{2}$

$\mathrm{I}_{c}$ Consistency Index of clay

$\rho$ Saturated density, $\mathrm{kg} / \mathrm{m}^{3}$

$\mathrm{L}$ Length of pile, $\mathrm{mm}$

$\mathrm{M}_{d}$ Dynamic bending moment, N.mm

$\mathbf{M}_{d \max }$ Maximum dynamic bending moment, N.mm

$\mathrm{S}_{u}$ Undrained shear strength of clay, $\mathrm{kN} / \mathrm{m}^{2}$

$\mathrm{V}_{s}$ Shear wave velocity, $\mathrm{m} / \mathrm{sec}$

$\mathrm{z}$ Depth of interest along the pile length

$z_{m d}$ Depth of maximum dynamic bending moment

$z_{m s}$ Depth of maximum static bending moment

\section{References}

[1] ASTM D2487, ASTM Standard Classification of soils for engineering purposes (Unified Classification System), 2002.

[2] A. Boominathan, R. Ayothiraman and J. Elango, Lateral vibration response of full scale single piles, in Proceedings of the 9th International Conference on Piling and Deep Foundations, Nice, France, 2002, 141-146.

[3] A. Tabesh and H.G. Poulos, A review of dynamic analysis of pile foundations, Research Report No: R757, Dept. of Civil Engineering, The University of Sydney, Australia, 1997.

[4] A. Tabesh and H.G. Poulos, The effects of soil yielding on seismic response of single piles, Soils and Foundations 41/3 (2001), 1-16.

[5] A. Velez, G. Gazetas and R. Krishnan, Lateral dynamic response of constrained-head piles, Journal of Geotechnical Engineering ASCE, 109 (1983), 1063-1081.

[6] B. Broms, The lateral resistance of piles in cohesive soils, Journal of Soil Mechanics Division ASCE, 90 (1964), $27-63$.

[7] D. Anandarajah, J. Zhang, G. Gnanaranjan and C. Ealy, Back - calculation of Winkler foundation parameters for dynamic analysis of piles from field test data, in Proc. of NSF International Workshop on Earthquake Simulation in Geotechnical Engineering, $2001,1-10$. 
[8] D. Angelides and J.M. Roesset, Nonlinear lateral dynamic stiffness of piles, Journal of Geotechnical Engineering Division ASCE, 107 (1981), 1443-1460.

[9] D. Badoni and N. Makris, Nonlinear response of single piles under lateral inertial and seismic loads, Soil Dynamics and Earthquake Engineering 15 (1996), 29-43.

[10] G. Mylonakis, Simplified model for seismic pile bending at soil layer interfaces, Soils and Foundations 41/4 (2001), 47-58.

[11] G.W. Blaney and M.W. O'Neill, Measured lateral response of mass on single pile in clay, Journal of Geotechnical Engineering ASCE, 112 (1986), 443-457.

[12] H. Dou and P.M. Byrne, Dynamic response of single piles and soil-pile interaction, Canadian Geotechnical Journal 33 (1996), 80-96.

[13] H.G. Poulos and E.H. Davis, Pile foundation analysis and design, John Wiley \& Sons Inc., New York, 1980.

[14] K.H. Stokoe and R.D. Woods, In-situ shear wave velocity measurement by crosshole test, Journal of Soil Mechanics and Foundation Engineering Division ASCE, 98 (1972), 951-979.

[15] K. Konagai, Data archives of seismic fault-induced damage, in Proc. of the 11th International Conference on Soil Dynamics and Earthquake Engineering, Berkeley, USA, 1, 2004, 5-13.

[16] K.V. Puri and S. Prakash, Observed and predicted response of piles under dynamic loads, in Piles under Dynamic Loads, Geotechnical Special Publication No: 34, ASCE (1992), 153-69.

[17] M. Katagiri and G. Imai, A new in-laboratory method to make homogeneous clayey samples and their mechanical properties, Soils and Foundations 34 (1994), 87-93.

[18] M. Kavvadas and G. Gazetas, Kinematic seismic response and bending of free head piles in layered soil, Geotechnique 43 (1993), $207-222$.

[19] M. Novak, Dynamic stiffness and damping of piles, Canadian Geotechnical Journal 11 (1974), 574-598.

[20] M. Novak, Experiments with shallow and deep foundations, in: Vibration Problems in Geotechnical Engineering, G. Gazetas and E.T. Selig, eds, ASCE, 1985, pp. 1-26.

[21] M. Novak and R.F. Grigg, Dynamic experiments with small pile foundations, Canadian Geotechnical Journal 107 (1976), $372-385$.

[22] M. H. El Naggar and K. J. Bentley, Dynamic analysis for laterally loaded piles and dynamic $p-y$ curves, Canadian Geotechnical Journal 37 (2000), 1166-1183.

[23] M.H. El Naggar and M. Novak, Nonlinear analysis of dynamic lateral pile response, Soil Dynamics and Earthquake Engineering 15 (1996), 233-244.

[24] M.W. Halling, K.C. Womack, I. Muhammad and K.M. Rollins, Vibrational testing of a full-scale pile group in soft clay, in Proc. of the 12th World Conference on Earthquake Engineering, New Zealand, 2000, Paper No: 1745.

[25] R. Dobry, E. Vicente, M.J. O'Rourke and J.M. Roesset, Horizontal stiffness and damping of single piles, Journal of Geotechnical Engineering Division ASCE, 108 (1982), 439-459.

[26] R. Krishnan, G. Gazetas and A. Velez, Static and dynamic lateral deflection of piles in non-homogeneous soil stratum, Geotechnique 33 (1983), 307-325.

[27] R. F. Scott, H. P. Liu and J. Ting, Dynamic pile tests by centrifuge testing, in Proc. of the Sixth World Conference on Earthquake Engineering, New Delhi, India, 2-4/199, (1977), 1670-1674.

[28] R.L. Kuhlemeyer, Static and dynamic laterally loaded floating piles, Journal of Geotechnical Engineering Division ASCE, 105 (1979), 289-304.

[29] R.L. Tucker, Lateral analysis of piles with dynamic behaviour, Proceedings of the Conference on Deep Foundations Mexico, 1 (1964), 157-171.

[30] R.Y.S. Pak, J.C. Ashlock, F. Abedzadeh and N. Turner, Comparison of continuum theories with measurements for piles under dynamic loads, in Proc. of the 16th ASCE Engineering Mechanics Conference, University of Washington, 2003, Paper No: 156.

[31] S. Bhattacharya and M.D. Bolton, A fundamental omission in seismic pile design leading to collapse, in Proceedings of the 11th International Conference on Soil Dynamics and Earthquake Engineering, Berkeley, USA, 1, 2004, 820-827.

[32] S. Narasimha Rao, V.G.S.T.K. Ramakrishna and M. Babu Rao, Influence of rigidity on laterally loaded pile groups in marine clay, Journal of Geotechnical and Geoenvironmental Engineering ASCE, 124 (1998), 542-549.

[33] S. Prakash and V. Chandrasekaran, Pile foundations under dynamic lateral loads, in Proceedings of the 8th International Conference on Soil Mechanics and Foundation Engineering, Moscow, 2-3/31, 1973, 199-202.

[34] S. Saha and D.P. Ghosh, Dynamic lateral response of piles in coupled mode of vibration, Soils and Foundations 26 (1986), 1-10.

[35] S.L. Agarwal, Discrete element analysis and its experimental verification for vertical piles under dynamic lateral loads, in Proc. of the 8th International Conference on Soil Mechanics and Foundation Engineering, Moscow, 2-3/2, (1972), 9-12.

[36] T. Nogami, J. Otani, K. Konagai and H.L. Chen, Nonlinear soil - pile interaction model for dynamic lateral motion, Journal of Geotechnical Engineering ASCE, 118 (1992), 89-106.

[37] T. Nogami and K. Konagai, Time domain flexural response of dynamically loaded single piles, Journal of Engineering Mechanics ASCE, 114(9) (1988), 1512-1525.

[38] V.M. Shaevich, Investigations of resistance of soil base to horizontal vibrations of piles, Soil Mechanics and Foundation Engineering Journal US, 2 (1990), 14-18.

[39] W.D.L. Finn, An overview of the behaviour of pile foundations in liquefiable and non-liquefiable soils during earthquake excitation, in Proc. of the 11th International Conference on Soil Dynamics and Earthquake Engineering, Berkeley, USA, 1, 2004, 57-67.

[40] Y. Han, Dynamic behavior of pile foundations, in Proceedings of the 9th International Conference on Piling and Deep Foundations, Nice, France, 2002, 173-178.

[41] Y. Han and M. Novak, Dynamic behaviour of single piles under strong harmonic excitation, Canadian Geotechnical Journal 25 (1988), 523-534.

[42] M. Ezekiel and K.A. Fox, Methods of correlation and regression analysis, 3rd Revised Edition, John Wiley \& Sons Inc., New York, 1959. 

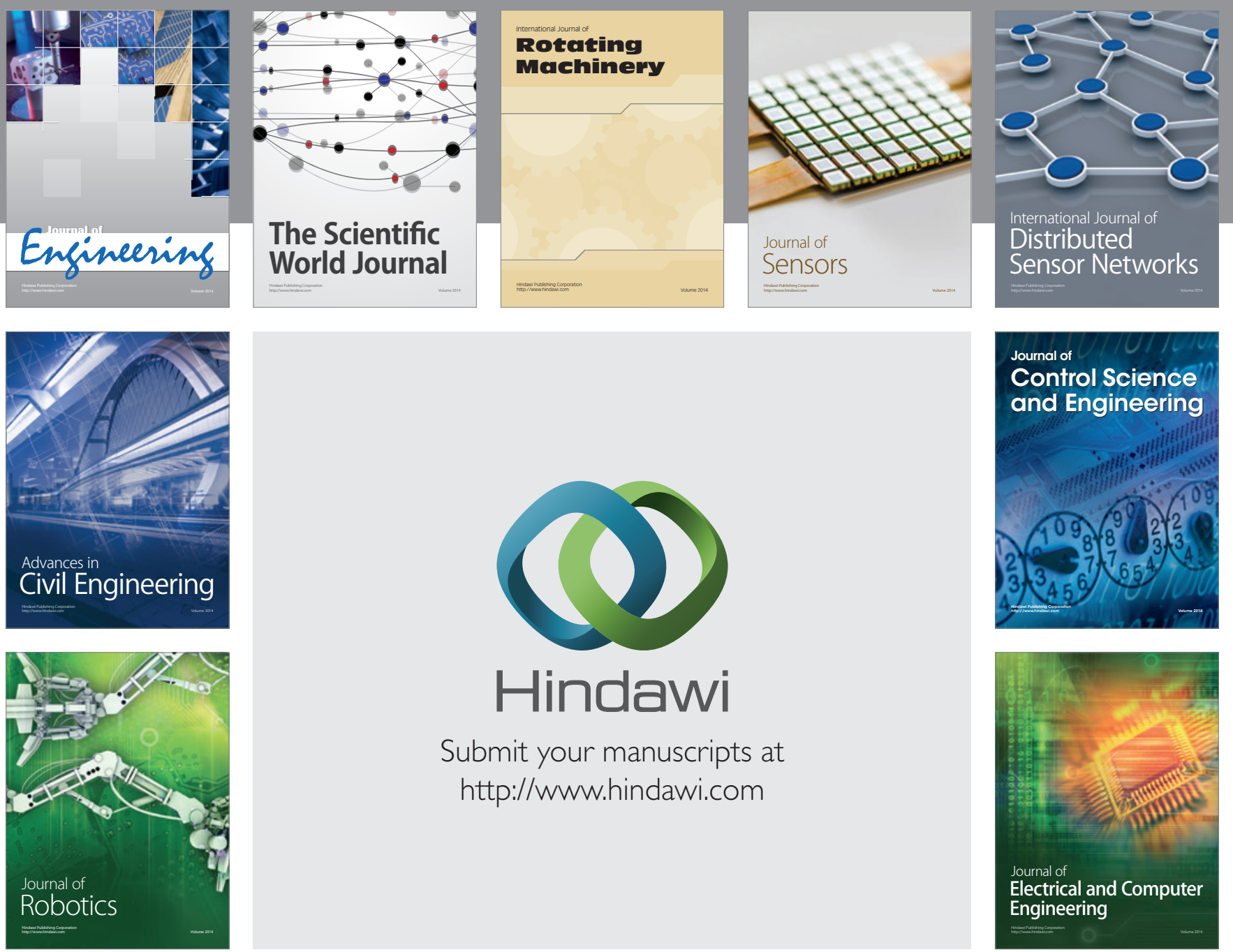

Submit your manuscripts at

http://www.hindawi.com
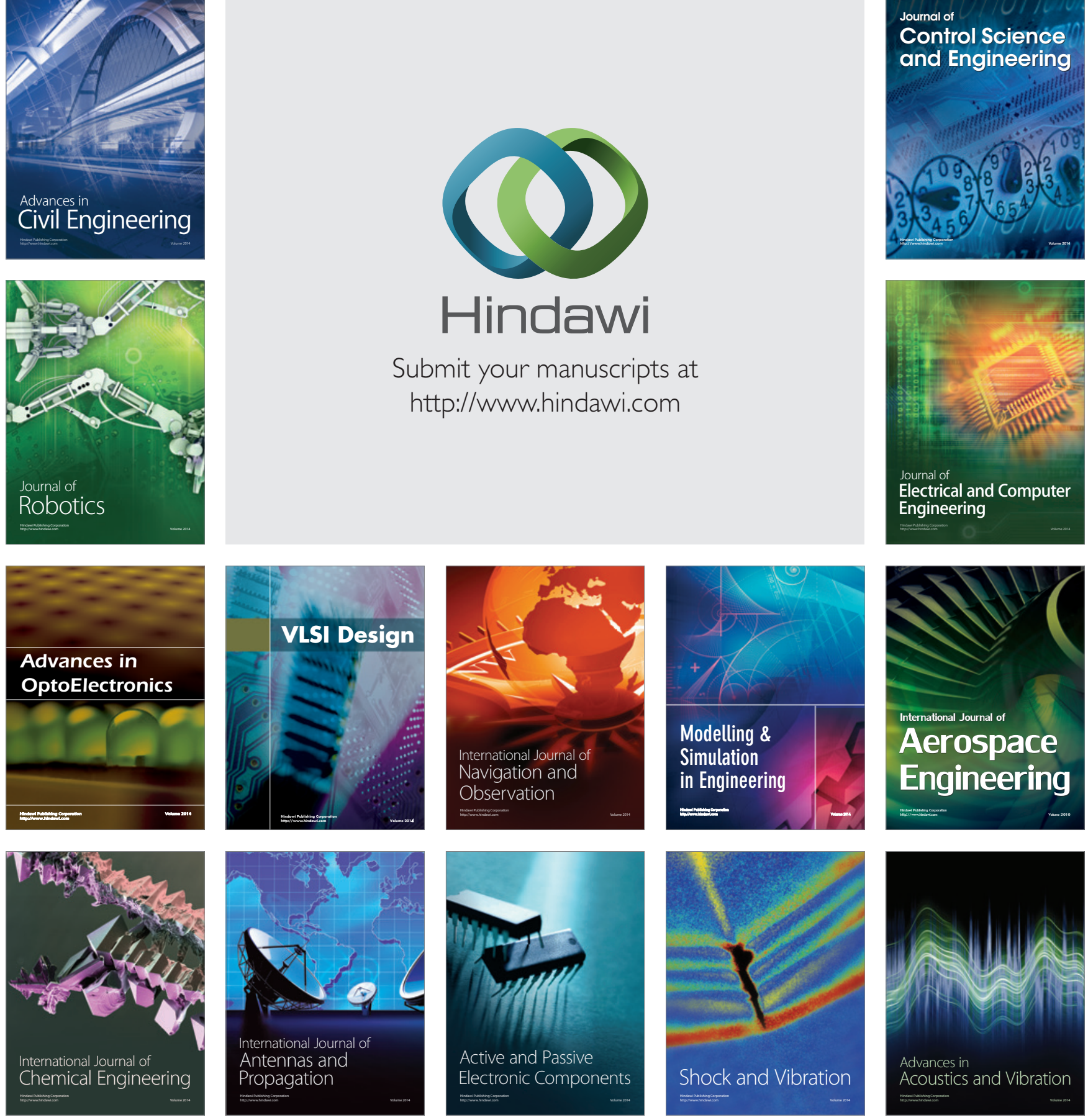